\title{
Relaciones de género: mujeres, sanmarquinas y chicheras
}

\section{Gender relations: women of San Marcos and corn beer makers}

\author{
Gianella Pacheco Neyra ${ }^{1}$ \\ Universidad Nacional Mayor de San Marcos. Lima, Perú \\ pacheco.gianella.neyra@gmail.com \\ ORCID 0000-0002-2352-6326
}

Citar como: Pacheco, G. (2019). Relaciones de género: mujeres, sanmarquinas y chicheras. Desde el Sur, 11(2), pp. 305-316.

\section{RESUMEN}

El presente artículo tiene como objetivo hacer una reflexión a través de la propia experiencia. Expone algunas situaciones adversas o desfavorables en las que podamos identificarnos como mujeres, investigadoras y específicamente como arqueólogas. Esta reflexión, además, busca visibilizar la importancia de las mujeres en el desarrollo de las sociedades prehispánicas, así como la necesidad de mujeres referentes en la investigación arqueológica. En la segunda parte del artículo se desarrolla la investigación sobre las chicheras de Magdalena de Cao y aspectos importantes que nos permitirán ejemplificar las problemáticas de las relaciones de género en la investigación.

\section{PALABRAS CLAVE}

Sociedades prehispánicas, relaciones de género, producción de chicha

\section{ABSTRACT}

The aim of this article is to offer a reflection upon personal experience, identifying adverse or unfavorable

1 Arqueóloga egresada de la Universidad Nacional Mayor de San Marcos y magíster en Antropología. Está encargada de la conservación en el Proyecto Qhapaq. Anteriormente fue jefa del área de conservación de la zona arqueológica de Caral, investigadora del Santuario Arqueológico de Pachacamac (Ministerio de Cultura) y directora del proyecto de investigación Tambo Colorado (Embajada de Francia). Investiga el uso de materiales y técnicas tradicionales, discursos de identidad y su empleo en la promoción de productos locales y tradicionales. Ha realizado diversas publicaciones y ponencias relacionadas con la conservación del patrimonio arqueológico. 
situations with which as women, and specifically as female archaeologists and researchers, we can identify. This reflection also seeks to shed light upon the importance of women in the development of Pre-Hispanic societies, as well as the need for female involvement in archaeological research. The second part of the article focuses upon research into the corn beer makers of Magdalena de Cao, and upon important issues that serve to illustrate problems associated with gender relations in the field of research.

\section{KEYWORDS}

Pre-Hispanic societies, gender relations, corn beer production

\section{Introducción}

La primera parte de este artículo es de tipo biográfico, debido a que nuestro contexto, capital familiar y circunstancias socioeconómicas repercuten de manera directa e indirecta en nuestros objetivos de investigación, así como en nuestras perspectivas como mujeres que investigan la sociedad del pasado. Con respecto a este punto Santa Cruz menciona algo muy interesante que nos permitirá entender estos aspectos desde nuestra condición: «Transmitir inquietudes, experiencias y logros que, en distintos terrenos, estén llevando adelante mujeres que —de algún modo- han podido vencer los obstáculos, para extraer de ellas las lecciones o la inspiración que puedan ser recogidos por otros» (Santa Cruz, 1982 , p. 49). En este sentido, nuestra biografía, nuestra vida académica e inquietudes sociales tienen mucho que ver con nuestros intereses de investigación con nuestras expectativas profesionales y con las actitudes frente a las barreas de género. Estas biografías y circunstancias a las que se refiere Viviana Santa Cruz están estrechamente vinculadas a dos aspectos el capital familiar y nuestras condiciones socioeconómicas.

El capital familiar se refiere a los valores, tradiciones, logros y creencias que nuestras madres y abuelas nos han heredado, ¿Quiénes han sido nuestras madres y abuelas? ¿Cuáles han sido sus luchas? ¿Qué barreras han vencido y cuáles no?

\section{Ser mujer y sanmarquina}

Ingresé a la universidad pública más grande del país, la Universidad Nacional Mayor de San Marcos, en 2000 y, como la gran mayoría de mis compañeros, crecí en la década de 1980 y pertenezco a la tercera generación de migrantes. En mi caso, migrantes de la sierra y costa sur que llegaron a Lima en búsqueda de mejores oportunidades hace 
aproximadamente 80 años. Los esfuerzos acumulados (capital socioeconómico) de mis generaciones pasadas me permitieron ser la primera en ingresar a una universidad. Este capital se acumuló especialmente gracias al esfuerzo de las mujeres de mi familia, mujeres que enfrentaron condiciones mucho más adversas y difíciles que yo he enfrentado, sin acceso a educación, con pocas oportunidades laborales y sin muchos referentes de mujeres independientes, fuertes y exitosas.

Yolanda, mi abuela, es una mujer brillante y autodidacta. No fue al colegio y aprendimos a leer juntas con el Coquito cuando ella tenía 60 años. Con sus ahorros, pudo otorgar carreras técnicas a sus tres hijas: enfermera, secretaria y auxiliar de nido. Esas eran las carreas disponibles a las que podían acceder, carreas técnicas y de «mujer». No había muchas opciones, tampoco hubo muchos medios económicos.

Mi madre, enfermera, es una lectora voraz. Nos crio y educó a mí y a mis cinco hermanos con historias y cuentos aleccionadores; cada cuento, una moraleja, una enseñanza. Gracias a su trabajo, pagó las academias para que mis hermanos y yo pudiésemos postular a universidades nacionales a las carreras que quisiéramos. Esta vez tenía más opciones y un poco más de holgura económica de la que ella pudo disfrutar. El compromiso de mi madre con nuestra educación y formación, incluso en momentos de adversidad económica, nunca se quebró. Nos conseguía libros y cuentos de segunda mano, enciclopedias antiguas de periódicos y engordaba nuestra «biblioteca», que consistía en unos estantes viejos atiborrados de libros viejos en un cuarto en el que pasé los momentos más fantásticos de mi infancia, leyendo cuentos y enciclopedias.

Con estas historias comprendí que a las mujeres de mi familia las oportunidades de estudiar les habían llegado tarde y sin muchas opciones. Las necesidades económicas y el machismo no les permitieron escoger. Pero estas barreras se fueron rompiendo en cada generación. Cuando me tocó el turno a mí y a mis hermanos el reto era desafiante. Teníamos que estudiar y trabajar, pero de alguna manera mis hermanas y yo quedábamos más expuestas a los peligros de la sociedad y con menos acceso a ofertas laborales. Después de llegar a casa por la noche, luego de estudiar y trabajar, no solo teníamos miedo a ser asaltadas en los paraderos, sino a ser agredidas sexualmente. Este miedo era compartido con muchas compañeras de clases, que, al igual que yo, luego de clases trabajaban de cajeras, recepcionistas e impulsadoras en supermercados para costear los pasajes, los gastos de las salidas de campo y las copias de los libros.

La educación en el Perú en las universidades nacionales, a pesar de que muchos no lo crean, no es gratuita. Es bastante cara, porque viene de todos los impuestos. Gran parte de esta inversión se desperdicia debido a 
que muchos estudiantes no logran culminar la carrera. El año que ingresé a la carrera de Arqueología lo hice con 81 compañeros más, de los cuales terminamos solo 30. Muchos dejaron la carrera porque no podían darse el lujo de estudiar y trabajar medio tiempo. Casi todos tuvimos problemas económicos, pero, además de esto, las chicas que ingresaron conmigo dejaban la carrera porque un embarazo no planificado se interponía. Muchas no habían tenido acceso a una buena educación sexual y no sabían cómo cuidarse de manera efectiva, a pesar de que la universidad contaba con un consultorio de planificación familiar en la Clínica Universitaria, que casi siempre estaba vacío. Era atendido por personal médico poco empático. Recuerdo que me preguntaron de manera inquisidora para qué quería cuidarme. Debo agradecer a mi madre que como enfermera siempre nos habló claramente y con mucho cariño sobre las responsabilidades que demanda ejercer una sexualidad.

A los 19 años y siendo estudiante universitaria, una cree que lo puede todo. Yo no podía perder la oportunidad que había llegado a mí después de tanto esfuerzo acumulado. Decidí salir de San Marcos con la capacidad de dar algún tipo de satisfacción a mi familia y así fui la única egresada con mención sobresaliente de mi promoción. Ese día empecé a pagar la deuda que tenía con mi madre y mi abuela.

Durante la crisis económica de 1990, yo tenía 8 años y veía cómo el silencio y la mirada de mis padres se clavaba en el televisor mientras Hurtado Miller, el ministro de Economía, nos anunciaba por televisión nacional el "paquetazo», la increíble alza de los productos básicos, y finalizaba con un «que Dios nos ayude». Una semana después de este anuncio, mis hermanos y yo fuimos retirados de nuestro pequeño colegio particular y trasladados a una gran unidad escolar en el Callao. Mis hermanos mayores fueron enviados a la casa de unos tíos a quienes les había ido bien en los negocios y podían ayudarlos a culminar sus carreras.

En el colegio al que llegamos mi hermana y yo las cosas eran diferentes. Para empezar, no había niños. Era un colegio solo para mujeres y los niños estaban en un colegio al lado, en otra gran unidad escolar. Sin embargo, éramos nosotras las que debíamos de salir 15 minutos después para que los niños no nos molestaran o faltaran el respeto, y éramos nosotras las que debíamos de usar la falda larga debajo de la rodilla para que no nos «metieran la mano». Además, debíamos usar un incómodo fustán que jamás antes había usado y del que no sabía su función, salvo darnos más calor en los meses iniciales de clases.

Entre otras cosas, aprendí a bailar salsa, pero lo más importante que aprendí en estas aulas es que las niñas somos solidarias: nos acompañábamos al paradero, nos esperábamos en la esquina de la casa si teníamos 
que hacer un trabajo grupal. Siendo aún pequeñas, sabíamos que estábamos en peligro. Con estas pequeñas amigas aprendí que la solidaridad es un clamor ante la injusticia y es asimismo un logro de género.

De igual forma, aprendí tempranamente que no siempre el que estudia triunfa, que la vida puede ser amarga e injusta. Muchas de las compañeras con las que estudié la secundaria no volvieron a pisar un aula nunca más, por razones económicas y también por el machismo. Entre todas las chicas destacaba mi mejor amiga, a quien por respeto llamaré Celia. Ella siempre obtenía los primeros puestos, ganaba los concursos de matemática, los juegos florales; una nerd con ojos de gato feliz. Celia vivía en condiciones precarias en un callejón que se caía por pedazos, pero estaba decidida a prepararse para ingresar a la universidad. Quería ser ingeniera ambiental. Por esos días yo ni siquiera sabía de la existencia de esa carrera, pero Celia tenía mucho más claros sus objetivos en la vida. Terminado el colegio, Celia comenzó a trabajar como impulsadora de vinos en un supermercado. Con ese dinero iba a pagar una academia preuniversitaria de nombre de filósofo griego de la avenida Arequipa. Celia sabía que volver de noche a su casa era peligroso, mucho más peligroso para ella, una jovencita delgada y pequeña, así que siempre su hermano y su tío la esperaban en el paradero. Una noche, su hermano y su tío trabajaron horas extras y no pudieron recogerla. Al verla sola caminado por el parque desolado, a dos cuadras del callejón donde vivía, dos hombres la detuvieron, la jalaron de los cabellos y quebraron sus sueños, la llevaron a un descampado y la ultrajaron. Celia nunca postuló a la universidad. Sus ojos de gato feliz ya no miraban como antes.

El año que ingresé a San Marcos volví a encontrar a Celia trabajando de cajera en un supermercado. En ese momento me sentí avergonzada, la abracé y sin querer bajé la cabeza. Me miré los pies y me sentí culpable, sentí que Celia merecía mucho más que yo el haber ingresado a la universidad. Celia, por el contrario, me daba una muestra de su fortaleza inquebrantable. Me abrazó y me dijo que estaba muy contenta por mí, que ella seguiría preparándose y postularía el próximo año. En silencio comprendí que a Celia nada la podría detener nunca más. Claro que sí, Celia, ojos de gato feliz, nada te puede parar, pensé.

Mientras muchas de nosotras llegamos a la universidad, por diferentes caminos, con diferentes capitales y provenientes de diversos contextos, todavía hay muchas chicas como Celia que siguen sorteando las barreras no solo de pobreza, sino de violencia de género. Es nuestro compromiso como ciudadanas, mujeres y sanmarquinas solidarizarnos con aquellas que quedaron atrapadas en esas barreras, porque pudimos ser una de ellas, porque todavía no estamos tan seguras. 


\section{Ser arqueóloga y mujer}

Ser arqueóloga nos da la oportunidad de trabajar no solo para satisfacer necesidades económicas, como quizás lo hayan hecho muchas de nuestras abuelas o nuestras madres, sino también necesidades personales y necesidades de reivindicación social. Nos da la oportunidad de ponernos en la historia de las sociedades y visibilizarnos como parte importante de su desarrollo.

Yo decidí ser arqueóloga después de haber ido al Museo Nacional de Antropología Arqueología e Historia del Perú. Tenía 6 años, estaba fascinada. El museo es donde están las cosas mágicas y los tesoros (un escape a la realidad, a la realidad muchas veces adversa), pero también es una fuente inagotable de conocimiento y emoción.

A pesar de mi fascinación, no me identifiqué con ningún personaje de ese museo. En las salas no había muchas mujeres representadas; de hecho, no había casi ninguna mujer. Pasaba por las salas de la prehistoria y había algunas maquetas con escenas de hombres cazando mamuts y algunas mujeres en la cueva, sentadas al fuego. El hombre, el gran descubridor, era el migrante, el que llegó por el estrecho de Bering con lanza en mano, un grupo de hombres siguiéndolos y con una o dos mujeres detrás del grupo. El hombre era la estrella y los títulos de los paneles también mencionaban solo al hombre como el protagonista de la prehistoria.

Había otras salas más adelante en la museografía cronológica, en la que estaban representados los paracas, médicos de gran talento y conocimiento que realizaban complicadas trepanaciones craneanas, y nuevamente se veía a un médico hombre en la conocida acuarela del un hombre paracas operando a otro hombre, acompañado de otro hombre más. Recuerdo que había una sala especial que hablaba sobre la metalurgia prehispánica. Nuevamente las figuras de las maquetas y las acuarelas eran hombres trabajando en hornos, haciendo hermosos collares y desplegando mucha tecnología en sus actividades. Finalmente, para representar un poco más las imágenes que vi en el museo, recuerdo que en una gran sala estaba el inca en una gran vitrina central, sentado en su anda, con su vara y apuntando con un dedo al horizonte. Si bien sabíamos que existía la colla, la esposa del inca, parecía no ser tan importante, ya que no estaba representada en una sala central ni tampoco tenía una vitrina para ella sola.

Al terminar la visita me quedé con la impresión de que desde la prehistoria las mujeres no estaban muy presentes o eran acompañantes de los personajes principales. Solo realizaban actividades domésticas como el cuidado de los niños, por lo que se veían como menos importantes y sin carga tecnológica. 


\section{Los museos y los discursos}

Ahora, ya de adulta, he tomado mayor conciencia de que los museos y sus discursos nos ayudan a formar ideas de quiénes hemos sido. Los museos cuentan historias y resaltan a sus protagonistas. Pero, en general, estas historias no incluyen a las niñas ni a las mujeres, lo cual no solo es injusto, sino que no es verdadero y afecta la autoestima de las mujeres.

¿Por qué pasa esto? Amelia Valcárcel nos explica que esto sucede porque hemos nacido dentro una tradición de dominio que nos dice que los hombres son inmanentes (constante) y las mujeres no; es decir, «los hombres no tienen que justificar su existencia por nada ajeno ni exterior a ellos».

La representación masculina es la norma, mientras que la representación femenina hay que justificarla. Por ejemplo, si nos imaginamos a unos expertos en metalurgia, asumimos que son hombres; si se encuentra una gran tumba con muchas ofrendas valiosas, asumimos que debe ser de un gran jefe. Asumimos que las mujeres no son importantes porque no hacen actividades importantes. Pero esto ha comenzado a cambiar. Las investigaciones cada vez más visibilizan a la mujer dentro de los contextos arqueológicos. Nuevas herramientas tecnológicas nos permiten contar la historia de los hombres y mujeres que formaron parte del desarrollo social prehispánico. La Dama de Cao es un ejemplo de ello.

Otro discurso bastante reiterativo en la arqueología se refiere a la división sexual del trabajo. En primer lugar, es necesario romper los prejuicios de que solo las mujeres realizan las actividades domésticas.

Otro prejuicio con respecto a las actividades domésticas es que estas no están cargadas de tecnología. Por ejemplo, a lo largo de la historia se ha considerado que la elaboración de alimentos es un proceso sencillo que no demanda de tecnología especializada, lo cual no es cierto. Procedimientos como la elaboración de bebidas alcohólicas o banquetes rituales demandan de complejas cadenas operativas cargadas de tecnología y simbolismo. Otros ejemplos importantes son la aplicación medicinal y el cuidado de los niños que involucran la trasmisión de tradiciones, de comportamientos $\mathrm{y}$, en resumen, de la formación de individuos y de la sociedad.

\section{Magdalena de Cao}

En esta segunda parte del artículo hablare sobre la investigación que he desarrollado al interior de la comunidad de Magdalena de $\mathrm{CaO}^{2}$ a partir

2 Localizada en el valle de Chicama, al norte de la capital del departamento de La Libertad, 
de mis preocupaciones personales y de mis intereses académicos, que, como hemos visto, están estrechamente vinculados.

En primer lugar, debemos tener en cuenta que Magdalena de Cao representa bien el proceso de desarrollo por el que atraviesan muchas zonas rurales de la costa norte (Pacheco, 2017). Este distrito se distingue por dos aspectos culturales muy importantes: por el notable descubrimiento de la Señora de Cao y también por la chicha de año, un tipo especial de chicha caracterizado por su largo proceso de fermentación, que la diferencia de otras bebidas fermentadas. Es un producto reconocido local y regionalmente.

Trabajé con los chicheros y las chicheras de Magdalena de Cao y establecí ciertas diferencias, por medio de las entrevistas realizadas como parte de mi tesis de maestría (Pacheco, 2016).

\section{Chicheras agentes de progreso}

Las ganancias generadas por la producción de chicha están dirigidas principalmente a la inversión en estudios superiores de los hijos mayores. Sus carreras están vinculadas usualmente al turismo, la agronomía, las ciencias contables, el derecho y las ciencias administrativas; en centros universitarios particulares (Universidad Cesar Vallejo) y estatales de TrujiIlo (Universidad Nacional de Trujillo).

Muchostestimonios expresaban el esfuerzo en dar estudios a los hijos, con la finalidad de que rompan la cadena de la pobreza y tengan mejores oportunidades. Valoran los estudios sobre otros recursos tales como la vestimenta:

Yo lo hago para ella [hija], para sus gastos. ¿No ves que le piden copias, una cosa, le piden otra cosa? Yo le doy 50, 100 soles... y no me pide ropa. Ella me dice: «Mami, cuando yo trabaje, ahí ya puedo comprarme mi ropa. Lo importante es la educación, la ropa no me hace, mami», me dice.

Victoria (58), productora de chicha

Además, la chicha es un recurso para forjar alianzas de reciprocidad y cooperación, valores estrechamente vinculados a esta bebida ancestral desde tiempos prehispánicos:

No es para mí [la ganancia de la venta de chicha], es para mi hija [...] porque ella paga media beca, 290. Yo quería la beca completa... Por eso le dije a don César [Acuña] cuando vino acá a almorzar, de ahí después se acercaron... Le dije a su hermano, don Óscar, que me

en la costa norte del Perú. 
ayudara... [Me dice] ya, ya, ya, y después cuando vino la última yo le dije: «iAy! Usted no es de palabra», le dije, «No me gustan las personas así... ¡Ustedes son amigos de muchos años! ¡Desde que hicieron su escuelita de acá. [...] Y ahora que estoy que le pido un favor, jay! ¡Viejacho de miércoles!», le digo. ¡Pidiéndole apoyo, ya va a terminar el otro año ya! ¡Con mis fuerzas! Tengo que darle su educación.

Sonia (46), productora de chicha

La historia de Sonia y Victoria presenta cómo las chicheras logran mejoras socioeconómicas en un contexto de escasas oportunidades académicas y laborales. La chicha de maíz, en este contexto, no solo representa un producto de valor económico, sino que también constituye un recurso simbólico que genera lazos de confianza y solidaridad. Este hecho se refleja en los tragos de cortesía que se ofrecen en las chicherías y picanterías, y las botellas que se obsequian a los consumidores constantes, los llamados caseritos. Estas acciones generan un vínculo de reciprocidad entre chicheras y clientes, y solidaridad y reciprocidad entre los chicheros, que se prestan ollas o se dan consejos para mejorar la calidad de la chicha. Las chicheras mayores son valoradas por sus conocimientos especializados.

\section{Tecnología aplicada en la producción de chicha}

La producción de chicha de año involucra, además de un gran esfuerzo físico, tiempo y un amplio conocimiento de técnicas, manejo de insumos y disposición de un espacio adecuado para realizar esta actividad. La cadena de producción de la chicha de año mantiene una lógica operativa, pero también conserva creencias que le otorgan a esta actividad importancia cultural.

Un indicador importante de la alta especialización tecnológica de la producción de chicha de año es la designación de un área especial para su elaboración. Las chicheras cuentan con un área de producción, ubicada dentro del área doméstica, que por lo general se comparte con las actividades de cocción de alimentos. No obstante, todas las chicheras cuentan con un espacio exclusivo para la fermentación. Las áreas de fermentación se caracterizan por ser ambientes oscuros y secos, ubicados habitualmente hacia un extremo de los patios o cocinas, donde no hay tránsito de personas ni animales. Además, están limitados por muros o cortinas, tienen cubierta de caña de totora o esteras, recubierta por una capa de mortero, y los pisos son de cemento o de tierra apisonada.

El cuarto de fermentación es un área muy importante, de acceso restringido, en donde solo la chichera puede acceder. Sonia, la chichera a la que entrevisto, me pide amablemente que la espere afuera, ya que la chicha es «celosa» y se pueda malograr si yo o alguien más entra. Esta 
creencia, bastante generalizada entre las chicheras, se basa en paramentos técnicos para mantener la temperatura y la humedad constantes en el cuarto y tener una óptima fermentación. Se evita la entrada y salida de personas que puedan provocar cambios térmicos e higrométricos. Restringir el tránsito de personas también cumple con la función de restringir el conocimiento de los procesos de producción a personas ajenas a la actividad. Para legitimar la restricción de acceso a los recintos se asumen creencias sobre la sensibilidad de la chicha a la presencia de personas extrañas, aludiendo que la chicha es «celosa» o que el «humor» de las personas afecta el proceso de fermentación. Ninguno de los entrevistados accedió a mostrarnos su área de fermentación y señalaron que la chicha podría malograrse.

A la chicha no le gusta que la estén mirando, mirando, mirando siempre. ¡Se malogra!... ¡La chicha es celosa!... ¡La chicha es bien celosa! Por eso se guarda en un cuartito especial. Se guarda ahí para que el que la prepara la vaya a cambiar de depósito. ¡Él nomás!

Jessica (35), productora de chicha

\section{Transmisión de conocimiento entre chicheras}

Los procesos, las técnicas y los secretos de la producción de chicha de año se aprenden en el ámbito familiar y comunal. Las mujeres, en su gran mayoría, aprenden esta actividad desde adolescentes, cuando ayudan en la elaboración de chicha a los familiares mayores, generalmente madres, abuelas y tías. Cuando son adultas, siguen solicitando consejos y ayuda a las chicheras de mayor prestigio, que suelen ser mujeres mayores, quienes algunas veces ya no elaboran chicha, pero mantienen conocimientos vigentes. Un tema frecuente de consulta surge cuando la chicha no alcanza el sabor deseado o se pone amarga. Se recurre a los consejos y la ayuda de chicheros de mayor experiencia, que suelen aconsejar la adición de ciertos insumos para «arreglar» la chicha.

Es una tradición de las abuelas, de las personas ya mayores.

Clara (66), productora de chicha

\section{La identidad de las productoras de chicha de año}

Los valores asociados a la producción de chicha de año son significativos dentro de las relaciones sociales. Todos las chicheros reconocen que la producción de chicha de año es una práctica tradicional local, que involucra valores de honestidad, solidaridad y esfuerzo, asociados a su identidad local y productiva.

La Dama de Cao constituye un fuerte referente para la identificación de mujeres líderes. Las chicheras utilizan esta iconografía para agregar valor simbólico a sus productos y refieren orgullosas que la Dama de Cao 
era de Magdalena de Cao, que sabía gobernar y que, al igual que ellas, era luchadora. Estos nuevos discursos generan otras perspectivas sobre la función de la mujer en las sociedades prehispánicas. A pesar de ello, he registrado percepciones machistas frente a estos nuevos discursos generados por las chicheras.

Finalmente, se registran algunos casos de ideas machistas con respecto a la función de la mujer en las sociedades prehispánicas.

Yo no creo que haya sido importante [la Señora de Cao]... Bueno, para mí no. Para mí, ha tenido que ser un hombre el que ha tenido que haber gobernado.

César (42), productor de chicha

\section{Contribuciones}

Contribución completa de Gianella Pacheco Neyra.

\section{Fuente de financiamiento}

Fondos propios de la autora.

\section{Conflicto de intereses}

No existe, no tiene relación alguna con la institución encargada. 


\section{REFERENCIAS BIBLIOGRÁFICAS}

Santa Cruz, A. y Erazo, V. (1982). Comunicación alternativa versus modelo transnacional femenino. Chasqui, Revista Latinoamericana de Comunicación, 4, pp. 44-49.

Pacheco, G. (2016). Los cambios en la tradición e identidad de la producción de chicha de año en Magdalena de Cao (tesis de magíster). Universidad Nacional Mayor de San Marcos, Lima.

Pacheco, G. (2017). La producción de la chicha de año, como recurso de desarrollo en el distrito de Magdalena de Cao. Turismo y Patrimonio, 11, pp. 27-35.

Recibido: $15 / 7 / 2019$

Aceptado: 28/10/2019 